\title{
MARGINAL UTILITY AND EXCHANGE VALUE
}

The Austrian theory derives advantage from conceiving cost as well as product under the aspect of value. Utility is taken as the sole source of value, and a specific function - namely, marginal utility - is made the definite regulator, or determinant of the latter. ${ }^{1}$ Cost of production being expressed in terms of value, the various factors enter into the problem under a single category, and thus it becomes a rational undertaking to attempt a definite correlation.

The fundamental thesis, the determination of value by marginal utility once accepted, the remainder seems easy. Value conceived as originating in the product is reflected in a faithful image to the paraphernalia of production.

The opponents of the doctrine have too often adhered to the sacrificial conception of cost, and have essayed to establish an equation between things generically unlike. Interpreting cost of production as personal irksomeness, pain, and the like, they have vainly sought to hold these elusive abstractions up to a concrete standard of measurement. The result has been that able men, although starting with a good working intuition that marginal utility is not the adequate solvent of exchange value, have ill succeeded in conducting their argument with clearness of thought and soundness of logic. For instance, Professor Macvane is led to drawing the inference that, "so far from controlling exchange value, it [marginal utility] is itself controlled by exchange value." 2

Now, under the hypothesis that exchange value and marginal utility have a common measure, there is no objection to saying that the measure of the latter is determined by that of the former,

1 "Value" in these Austrian formulæ is, of course, not free from the suspicion of ambiguity, which, if well founded, discredits the results. This paper concerns itself with exchange value only; but, as the Austrian terminology is of necessity largely employed, misapprehension is guarded against by using the full designation wherever the meaning might otherwise be doubtful.

${ }^{2}$ Quarterly Journal of Economics, Vol. VII, p. 250. 
since, as it happens, exchange value is more directly susceptible of measurement - just as we may say that the length of a roll of cloth is determined by a yard-stick, or by another piece of cloth of known length. But Professor Macvane's argument is that exchange value regulates or controls marginal utility. This is hardly a sane interpretation of the historical sequence. Marginal utility, as well as general utility, obtains before exchange; so that, if there is any causal relation, it must take its rise, at least, in marginal utility. ${ }^{3}$

One of the great exponents of the Austrian view, Wieser, introduces the conception of "natural value" into the discussion. Now, as long as he adheres to that notion of value, there is no fault to be found with his conditioning it in, or indeed identifying it with, marginal utility. Value and utility are synonymous in that conception, each expressing the satisfaction obtainable from consumption goods. Either may be substituted for the other without endangering the coherence of the thought. We may say,

${ }^{3}$ There are cases in which the marginal utility is not free from the influence of exchange value. There is, in fact, a class of cases - namely, luxuries - where the high "cost" enhances "utility." Costly gewgaws are prized more as tokens of affluence, or some kindred sentiment, than for any other species of service. This points to a tributary to the stream of causation. It is a case in which cost of production is an agency in the creation of utility, the influence of the agent being reflected from exchange value, or price, directly to the object of desire, which in turn manifests the effect by an increased capacity for gratification.

If some genius should devise a method of manufacturing inexpensively from coal the genuine diamond - an article that would deceive the expert as well as the ordinary observer - no one would be disposed to deny that the utility of that brilliant would suffer, purely out of consideration of the exchange value or " cost."

"We find things beautiful, as well as serviceable, somewhat in proportion as they are costly. With few and inconsequential exceptions, we all find a costly hand-wrought article of apparel much preferable in point of beauty and serviceability to a less expensive imitation of it, however cleverly the spurious article may imitate the costly original; and what offends our sensibilities in the spurious article is not that it falls short in form or color, or, indeed, in visual effect in any way. The offensive object may be so close an imitation as to defy any but the closest scrutiny; and yet so soon as the counterfeit is detected, its æsthetic value, and its commercial value as well, declines precipitately." $-\mathrm{T}$. Veblen, The Theory of the Leisure Class, p. 169 .

Still, while we regard as trustworthy the general observation that exchange value is not the regulator of marginal utility, the example tends to show that the causative agency, working out economic effects, is by no means a simple one. 
indifferently, "total value" or "total utility." We may use our pleasure also as to "marginal value" and "marginal utility." And if, in any discussion, it is found convenient to replace the former expression with "natural value," there is possibly no objection to that. But thus far we are using a value-concept appropriate to individual economy. "Utility," or "value," in this sense, is a suitable term for service in the calculus of individual pleasure or satisfaction.

But when Wieser enters upon the discussion of exchange value, his admissions seem to stand up in protest against his formal conclusions. Conceding that in practical life exchange value diverges from the natural, he observes that it is largely due to the fault of our systems, so that in a natural economy there would be, at least, a nearer approach to coincidence. Here is the explanation of the present divergence:

The relation of natural value to exchange value is clear. Natural value is one element in the formation of exchange value. It does not, however, enter simply and thoroughly into exchange value. On the one side it is disturbed by human imperfection, by error, fraud, force, chance; and, on the other, by the present order of society, by the existence of private property, and the differences between rich and poor - as a consequence of which latter a second element mingles itself in the formation of exchange value, namely, purchasing power. In natural value goods are esteemed simply according to their marginal utility; in exchange value, according to a combination of marginal utility and purchasing power."

If we should take the above passage as the sole index of Wieser's views on the question at issue, there would be nothing to provoke unfavorable comment, especially as he immediately adds, by way of strengthening the effect: "Exchange value, even when considered perfect, is, if we may so call it, a caricature of natural value; it disturbs its economic symmetry, magnifying the small and reducing the great."

It is the exchange value as we find it in our existing environment that calls for explanation and should engage our study. We are not immediately concerned with "natural economy;" so that, if elements other than marginal utility are found in the exchange value of current experience, the machinery of regulation is not simple, but complex.

"Natural Value, p. 6r. 
That there is a disparity between exchange value and marginal utility, so unreservedly admitted by Wieser in the passages quoted, it is the purpose of this paper to emphasize. It will be the aim to show that exchange value never does, and never can, in the nature of things, coincide with marginal utility. ${ }^{5}$

For the sake of simplicity, let us divide utilities into three groups - food, shelter (including clothing), and luxuries. The supply of each group may be measured along the line $O X$ (see diagram) from the point $O$. The marginal utility may be measured in a direction perpendicular to $O X$, that is, in the direction $O Y$.

Food being the most important of the groups, being indeed absolutely essential to life, its marginal utility evidently will be

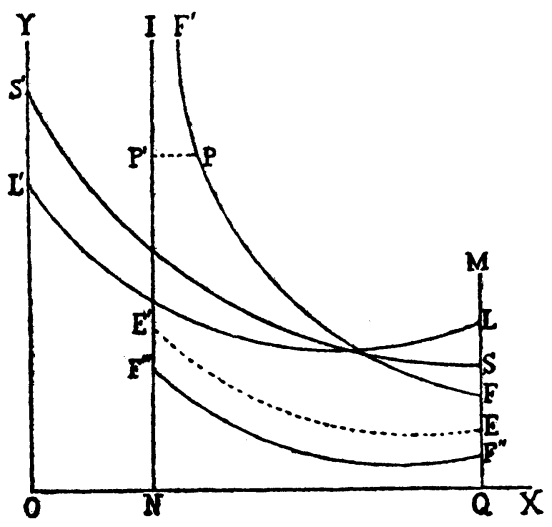
infinity in the early stages of its supply, or until a quantity is reached that is just equal to the task of maintaining the lives of the social units. Let this quantity be represented by $O N$. Then if $I$ be supposed at an infinite distance from $N$, the line $N I$ will represent the marginal utility of food as long as the supply does not exceed $O N$. When it passes that point, and the increasing abundance causes the urgency of desire rapidly to abate, the corresponding decline of utility may be represented by diminishing perpendiculars erected upon $O X$ and terminating in the curve

"In a very suggestive article, "Proposed Modifications in Austrian Theory and Terminology," in the Quarterly Journal of Economics for May, 1902, H. J. Davenport calls attention to the fact that in making comparisons, marginal utility must be taken in a relative sense, absolute utility being incommensurate. Probably no one will dispute the soundness of this view. Exchange value, considered quantitatively is a relative conception, a ratio; and marginal utility must be reduced to the same category, or comparisons will be futile and meaningless. With this avowal, the simpler expression "marginal utility" is retained in the text. 
$F^{\prime} F$. At the last stage, when the supply reaches $Q$, the marginal utility $^{6}$ of food will be represented by $Q F{ }^{7}$

In the same way $S^{\prime} S$ is drawn as the curve of marginal utility for shelter. As shelter perhaps is not absolutely essential to life, ${ }^{8}$ its marginal utility for the first unit of supply may be taken large, although not infinite, say $O S^{\prime}$. As in the case of food, the marginal utility of shelter, when the supply reaches $Q$, is represented by a distance along $Q M$, say $Q S$.

Likewise $L^{\prime} L$ may be drawn as the curve of marginal utility for luxuries.

If $O Q$ represents the number of units in each group at some specific period, the distances $Q F, Q S, Q L$ will represent the various marginal utilities belonging to the three groups. ${ }^{9}$

- In this schematic representation $F^{\prime} F$ would be called the curve of marginal utility. It should be borne in mind that marginal utility is not measured along this line. The meaning of the curve is that it is formed of the terminal points of perpendiculars which are erected upon $O X$ from points that indicate the measure of the supply.

${ }^{\top}$ Marginal utility being, for purposes of comparison, a relative quantity, as stated in note, p. 392, these perpendiculars represent the ratios subsisting between the utility of a unit of food and that of some standard unit, say, one dollar, or of the equivalent of one dollar in other supplies.

The objection may be made that with the supply of food at $N$, there might be in the market some purchasers so circumstanced that the marginal utility of food to them would be quite finite, and consequently it would be incorrect to put it generally that the marginal utility is infinite. The reply is that under the conditions supposed (I) such favored ones would be so few that they can be ignored; or (2) they can be classed with the sellers; or (3) it can be stipulated that the larder of every purchaser of food is empty at the time that the supply reaches $N$ : or (4) we may take the point $N$ nearer $O$, so as to represent a still more restricted supply.

The diagram is general in that it may be supposed to represent the relations of any one purchaser to the market. The individual variations are not such as to affect the vital relations that constitute the argument. For instance, the curve $F^{\prime} F$ will vary in height for different buyers, but the essential characteristic of its superior altitude to $E^{\prime} E$ at corresponding points is never wanting.

${ }^{8}$ It will not affect the argument if we regard the marginal utility of the initial supplies of shelter to be infinite, thus carrying the point $S^{\prime}$ to an infinite distance from $O$.

-The supplies of the different groups are represented by distances along the same line $O X$, although the units of the various groups are quite diverse. Accuracy, for our purpose, is not material, and is made subordinate to diagrammatic simplicity. This will explain, too, the apparent equality of the supplies in 
Now let us suppose the food supply cut off to the point indispensable to life - that is, to the point $N$ - the remaining groups not suffering any diminution. It is evident that the marginal utility of food will rise to infinity, represented by $I$.

At this critical stage of the supply, what will be the exchange value of food? Plainly, it cannot rise to infinity. Exchange value, quantitatively, is essentially a ratio; and as the quantities in the various groups are all finite, the ratios are finite.

The exchange value of food, under the specified conditions, could not be forecast with precision, since the state of competition and other circumstances of the market would make themselves felt; but necessarily it would be finite - say $N E^{\prime}$ - while the marginal utility is infinite at $I$.

The curve of exchange value of food will start then at some point $E^{\prime 10}$ infinitely below the corresponding point of marginal utility. What course will this curve take as the supply of food is increased? Obviously, there will be no sudden leap to the curve of marginal utility. Granting this, it is evident that the former curve will remain at an inferior altitude for a considerable distance. The question is: Will they ever meet? That is, will the exchange value of food ever equal the ratio of marginal utility?

To answer this question, it will be convenient to view the subject from a slightly different standpoint, or, at least. to examine the circumstances more minutely. When we represent the marginal utility by $N I$ - that is, by infinity - what is meant is that this is the marginal utility as viewed by the purchaser. He will give all the world, if he possesses it, for the food essential to life. The seller, however, has an excess, viewed from the standpoint of his personal requirements. The marginal utility to him is the various groups. Different points along $O X$ might have been taken for this purpose, but this would have somewhat complicated the diagram. Besides, the actual supplies at any time could be divided into the same number of units, giving, of course, quite an arbitrary unit for each group ; but the aggregate of such units, in each case, would be correctly represented by $O Q$.

${ }^{10}$ Theoretically, the curve of exchange value should begin at some point in $O Y$, and would do so in the ordinary case; but, in our illustration, if the supply of food were less than $O N$ - that is, less than is indispensable to the lives of the society - there could be no such thing as economic exchange. Anarchy and riot would necessarily prevail. 
quite low. Rather than retain his surplus, he will dispose of it at a low rate, say, about $N F^{\prime \prime \prime}$. In the diagram the conditions of the market are supposed to be such that the producers can command $N E^{\prime}$, which, of course, represents the actual exchange value.

This means that a complete diagram of marginal utility must show two curves for each commodity, the one drawn from the purchaser's point of view, the other from the seller's. In our diagram the inferior curve of marginal utility for food will start at $F^{\prime \prime \prime}$, and will follow a course that may be supposed to terminate at $F^{\prime \prime}$.

There arises now a complex of queries: (I) Will the curve of exchange value meet either of the curves of marginal utility? (2) Will the two latter curves ever meet? (3) Upon the basis of an affirmative view of proposition (2), what happens to the curve of exchange value at the time of coincidence? A correct account of the phenomena vaguely foreshadowed in these queries is full of significance in the Austrian controversy.

Let us consider the case of barter under the simplest conditions - say, two men living on an island isolated from the world. Suppose at a specific time each finds himself in possession of five bushels of corn and five bushels of potatoes. Now, if the marginal utility of corn is the same as that of potatoes to A, and this is a faithful transcript also of the mind of $B$, there will be no disposition to make an exchange. Again, whatever the ratio of these margins, in case of agreement between A's and B's estimates, there will be no economic ground for an exchange.

But let us suppose a difference. A may consider that he can derive the maximum of satisfaction from the consumption of the two kinds of provision in the proportion of six bushels of corn to four bushels of potatoes. If B's choice varies from this, there will be an incentive to exchange. Now, if we suppose A ignorant of the state of B's mind, he may reason somewhat as follows: "This fifth bushel of potatoes will afford me about the same satisfaction as half a bushel extra of corn. ${ }^{11}$ The exchange on

${ }^{11}$ That a consumer should elect his supplies of corn and potatoes in the proportion of $6: 4$ does not mean that the ratio of marginal utility is $6: 4$. That ratio would depend on the man and on the state of his supplies. The only circumstances under which one could lay down a law would be when the supplies 
that basis, however, will not mend matters for me; but if $B$ will give me anything in excess of half a bushel of corn, the bushel of potatoes is at his command."

B may take precisely the reverse view; that is, his choice may be six bushels to four in favor of potatoes. He may covet an extra portion of potatoes so much that he puts the utility of his fifth bushel of corn on an equality with that of a third of a bushel extra of potatoes. He stands ready to exchange at any ratio more favorable than $1 / 3:$ I (the $1 / 3$ representing potatoes).

Now, should there be a disposition on either side to secure the greatest advantage possible, especially if that one should be acquainted with the state of mind of his comrade, the exchange might take place on a basis close to one of the above ratios. In either event, one would make a slight gain of utility, while the other would realize a considerable gain. ${ }^{12}$

The point to be noticed is that the actual basis of exchange marks a new ratio, coinciding with neither of the above, but lying between them. In the case of corn, compared with potatoes, the marginal utility is $I: I / 2$ (2) for $A$, and $I / 3: I(I / 3)$ for $B$. The exchange value must lie between 2 and $1 / 3$, since an exchange on the basis of either ratio mentioned would be a futile transaction for one of the parties. ${ }^{13}$

stand $\sigma: 4$. Under the hypothesis that this ratio of supply realizes the maximum of satisfaction, he would be unwilling to disturb it, indicating the equality of the two margins at the time the ratio of provision is $6: 4$. As the law of marginal utility demands a change with change of provision, the ratio of marginal utility would be a function of two variables - namely, the changing provision and the mood of the person. It could be known only experimentally.

${ }^{12}$ Perhaps, in our illustration, friendliness or comradeship would temper the "trading" instinct, and a mutual exchange of confidences would decide the matter in favor of an even ratio, bushel for bushel; but this is not what happens in an ordinary modern market.

${ }^{13}$ Some would say that the ratios 2 and $1 / 3$ in the illustration mark points of indifference as to exchange. But the situation is described more accurately by saying that no exchange would take place. No motive exists on either side, and a motive of gain is indispensable to an economic transaction. Besides, the mere bother of exchanging demands economically some compensation, and hence will cause the exchange value to vary from the point of marginal utility. In the modern industrial system this bother becomes "commissions," "salaries," etc. selling expenses - and, of course, must be definitely reckoned with. 
In these cases of diverse margins of utility the conclusion seems inevitable that the exchange value must vary from either. Indeed, if we insist on a coincidence, with which ratio must it coincide?

There remains the case of coincidence of the two margins of utility. This happens obviously when the two parties are satisfied with their existing supplies. If $A$ and $B$ have each five and five of corn and potatoes, and the final utility to each is I : I (I), and the knowledge is mutual, neither one will contemplate an exchange. This marks the so-called point of indifference. It rather marks the suspension of market operations. An exchange would be a futile transaction. It would not take place. ${ }^{14}$ There would be a break in the curve of exchange value corresponding to the point of coincidence of the two margins of utility.

We may transfer this logic to the diagram with identical results. The intervention of a medium of exchange will not alter the situation. If a medium is used, it stands to the purchaser for a specific measure of utilities - miscellaneous, of course, and consequently more likely to bring about unexpected results; but as marginal utility is a matter of estimate simply, this will not affect the problem - and this measure of utilities is weighed against the commodities for sale in the same way as in case of simple barter. If we suppose exchange value to equal the marginal utility of the commodity offered for sale, in the estimate of the purchaser, the exchange would be futile to him. If it is so low as to parallel the marginal utility, in the estimate of the seller, the exchange would be futile to the latter. If the two margins of utility (estimates of seller and buyer) coincide, there would be no exchange. The purchaser will not give in excess of his estimate of the marginal utility, and the seller will not accept an offer short

${ }^{14}$ Supposing that, under the circumstances of equal supplies and equal margins of utility, A and B should make the exchange of a bushel of potatoes for a bushel of corn. This would at once disturb the equilibrium, as it would alter the ratio of provision from $5: 5$ (unity) to $6 ; 4$. Now, according to the law, an alteration of this ratio entails a variation in the ratio of marginal utility. The postulated exchange would work to the disadvantage of both parties. Even if one ear of corn were exchanged for one potato, theoretically there would be some, although a slight, disturbance. 
of his own estimate. They will not exchange on even terms, as the transaction would be futile to both - there would be no exchange.

These illustrations can be multiplied ad infinitum, and with the same result. They prove, at least, that the measure of marginal utility is not the measure of exchange value. The disparity at times may be small, or it may be infinite, as in the case of the diagram. There is always some difference or no economic exchange.

In many of the industries under modern organization, the lower marginal utility is practically zero, since goods are manufactured exclusively for the market. The Austrians have realized the seriousness of this excessive disparity between the two limits. With their customary ingenuity, they discard, in these cases, this lower limit - the producer's estimate of marginal utility of his own wares, his "subjective valuation" of them and resort to substitution. The substitute seemingly approved by Wieser is designated subjective exchange value, and is defined as the subjective valuation of the goods got in exchange for the seller's commodity. ${ }^{15}$

"Although the commodity has no value in use to the seller, yet the price which he receives has an indirect value in use to him, since it enables him to buy goods of direct value in use." ${ }^{16}$

As the large entrepreneur does not contemplate the investment of his proceeds, except to an insignificant extent, in goods for personal use, it is difficult to see how the new determinant applies to his case. What he desires most of all is to pay his bills. The price is a cold, abstract proposition that has not a suggestion of subjective exchange valuation in it. His supreme interest in the selling price is that it may suffice to cover his expenses of production, including a generous profit for himself.

The introduction of subjective exchange value into the con-

${ }^{15}$ Böhm-Bawerk, Positive Theory, pp. 166, г67: "The amount of subjective exchange value ... obviously coincides with the amount of the use value of the goods got in exchange.... The amount of the good's subjective exchange value, therefore, is to be measured by the marginal utility of the goods got in exchange for it."

${ }^{18}$ Wieser, Annals of the American Academy, Vol. II, p. 625. 
sideration of price is made without apology for withholding from it universal application. It is explained that in a small market, in isolated exchange, "the price is determined somewhere between the subjective valuation [marginal utility] of the commodity by the buyer, as upper limit, and the subjective valuation of the seller, as lower limit." 17 In a large market this lower subjective valuation is discarded in favor of some higher valuation which Wieser identifies with "subjective exchange value." But why does not the new determinant apply equally well to a primitive market, to "isolated exchange" ? Rather, why has it not even a more plausible application, in the case of simple barter? We have seen that the large entrepreneur has no occasion to look beyond the objective aspect of the price, since the returns are devoted, not to personal use, but to the liquidation of accounts. In the case of barter, however, where each exchanger has in view the personal consumption of the commodities under negotiation, the very statement of this circumstance avers that exchange is contemplated from the standpoint of subjective valuation.

If $\mathrm{A}$ has a little superfluous meal, but is short of potatoes, and B's situation is just the reverse, what is the moving principle of exchange between them? Plainly, the consideration of the subjective use of each other's provisions. Now, if A barters a sack of meal for one and a half bushels of potatoes with a view to personal consumption, the store received has not a mere objective significance to him. He exchanges because he craves potatoes as an article of diet, and he evidently concludes the exchange in view of his comparative valuation ${ }^{18}$ of the two species of provision.

It seems plain from the above passages that the notion of subjective exchange value is associated with a small market, or isolated exchange, rather than with a large market. But this fact does not argue that the notion has anything to do with the determination of exchange value in any market. On the contrary, the very genesis of subjective exchange value shows that the office ascribed to it is an impossible one. It comes into calculation, of

${ }^{17}$ Positive Theory, p. I99.

${ }^{18}$ Notice that this is not subjective exchange valuation. 
necessity, subsequently to the fixing of objective exchange value; for how can one make a subjective valuation of a thing unless he first knows what the thing is? And the thing itself is the exchange value in its objective character, or, simply exchange value, as it is usually designated. ${ }^{19}$

This conclusion follows, too, from the Austrian definition of the notion in question. For instance, "The amount of subjective exchange value .... obviously coincides with the amount of the use value of the goods got in exchange." 20 But this "use value" cannot be determined without first knowing what we are thus evaluating, that is to say, without first knowing the amount of the "goods got in exchange," which is the objective, or, simply, the exchange, value.

Böhm-Bawerk's expansion of the above definition makes this point still clearer. He adds: "The amount of the good's subjective exchange value, therefore, is to be measured by the marginal utility of the goods got in exchange for it." But the marginal utility (to the receiver) of the goods got in exchange is confessedly higher than the exchange value, for, as Böhm-Bawerk truly says: "The price [exchange value] is determined somewhere between the subjective valuation [marginal utility] of the commodity by the buyer, as upper limit, and the subjective valuation of the seller, as lower limit." 21 In our illustration, A's subjective valuation of the one and a half bushels of potatoes is in excess of that of the sack of meal; otherwise he would not exchange. Say it is equal to that of two sacks of meal. Then the proposition may be stated suggestively as follows: A's subjective exchange valuation of one sack of meal corresponds to his subjective valuation of two sacks of meal. But how could he determine this relationship without having in mind the definite measure of potatoes received; that is, without first knowing the objective, or, simply, the exchange, value?

${ }^{19}$ To reach subjective exchange value, in the illustration, there must be an evaluation of the one and a half bushels, the definite quantity received in exchange. The evaluation of potatoes without reference to this definite quantity would be simply subjective valuation, and takes place, as has been explained, before exchange.

20 See note I 5, p. $398 . \quad{ }^{21}$ Positive Theory, p. 199. 
There can be a subjective valuation of two commodities put up against one another; for instance, A can compare the use values of meal and potatoes; in fact, he cannot avoid doing so in contemplating an economic exchange, but he cannot determine the subjective exchange value of his sack of meal without first knowing, objectively, the terms of the exchange. ${ }^{22}$

The realization of the zero subjective valuation (lower marginal utility) is not confined to markets operated by the great captains of industry. It is a common experience. In a comparatively small or primitive market the marginal utility may drop to zero or below. It will be instructive to study such a case.

A small fruit-grower, located well away from the centers of industry, has a crop of apples. Conditions are such that the expenses of picking, packing, and freight will eat up the price. As he has more than his family can possibly use, his subjective valuation (marginal utility) of them must be zero. It is even less favorable than that. The apples are a burden to the trees and will rot on the ground. Their utility is really negative. He will gladly give them to anyone who will relieve his orchard. Possibly some one can be found who will take them on these terms.

Exchange value, in this case, is zero. But what is true of the marginal utility? To the second party (the "purchaser") the marginal utility must be positive, else he would gain nothing by the transaction. ${ }^{23}$ To the fruit-grower ("seller"), however, the subjective valuation must be negative, else there would be no gain to him from the transfer. The record then stands: upper

${ }^{22}$ It is proper to state that Böhm-Bawerk himself does not expressly apply subjective exchange value to the determination of price, or exchange value. At the same time he is responsible for introducing the notion into the general exposition of the subject, and it has naturally led to confusion and error. This author attempts to resolve the difficulty of the zero use valuation by a method that seems to confirm its validity as a limiting function. He first dismisses the use value to the seller from the calculation, claiming that price is determined in this case solely by the purchasers' valuations. Then he explains that in certain contingencies the zero limit is installed again. This admission, or exception, amounts to a reversal of the primary affirmation, since it is equivalent to saying that, although zero is the real lower limit, we must be careful to bear in mind that the price rarely reaches that point, even approximately.

${ }^{23} \mathrm{He}$ may be short of stock feed, or there may be other uses not feasible to the fruit grower. 
margin of utility ("buyer's"), positive; lower margin ("seller's"), negative; exchange value at the intervening point, zero.

This case may well be one wherein all the ratios are minus. The "buyer" may have no use for the crop, and yet he may have facilities for clearing the orchard at less trouble and expense than the owner. Here we have conditions suitable for an economic transaction. The marginal utility to the "buyer" is negative in slight measure; to the "seller," it is the same in greater degree. The latter "pays out" (negative of "price" or "exchange value") something to effect the "exchange." The same logic, used when the functions are positive, locates the negative price, or exchange value, at a point between the negative estimates of marginal utility (negative subjective valuations)..$^{24}$

By the extension of the notions of utility and value into the

${ }^{24}$ Cases of negative utility in actual experience are numerous. The air at the earth's surface has ordinarily the marginal utility, zero. In mines, in diving-bells, in workshops and other buildings, appliances are used to renovate the life-giving fluid. In these cases both the fresh and the vitiated air have exchanged value, the one positive, the other negative. The owner of the building stands in the relation of buyer; the installer of the appliance, as seller; fresh air is the commodity. In the reverse aspect of the case, the former is seller; the latter, buyer; and vitiated air is the commodity. The two margins of utility of the first commodity evidently are positive and zero, the price paid, or exchange value, lying between. For the second commodity, vitiated air, we have the upper margin of utility (the subjective valuation of the installer of the appliance) at zero; the exchange value (the seller pays, the buyer receives, in this case) is negative; and the lower margin of utility (to the owner of the building) is a lower negative.

Considerable has been written to the effect that "cost," in the sense of "pain" or "sacrifice," associated with labor and capital, should be taken as the negative of utility or value. So far as the matter affects economics, however, the text presents the simple and natural analysis of the relation. All concepts pass from the positive to the negative form through the vanishing point, without generic change. In the above illustration, we see how marginal utility and exchange value pass naturally into a negative relation.

Notice that the negative functions of these notions apply to the same concrete objects that give rise to the positive relations. In the case of the text, apples are the concrete source of these positive and negative functions. Here we have indicated the proper test of the validity of deductions as to positive and negative, relative to the economic functions of utility and value.

The so-called "sacrifice" or "pain" has its negative aspect also, as may be realized by considering a complete scale of its gradations. As the sense of pain diminishes, it passes through the vanishing point to the negative form of pleasure. 
negative region, we have a comprehensive survey of the zone of exchange value, with its potential motion along a scale that includes the vanishing point, zero. The margins of the zone coinciding with the margins of utility mark the limits of the fluctuation of exchange value. ${ }^{25}$

Having seen that the measure of marginal utility is not the measure of exchange value, it remains to inquire more narrowly into their relation. It will be conceded at once that inequality of dimension between homogeneous phenomena does not of itself exclude causal relation. The water at the earth's surface is the source whence fog and cloud derive their substance; and yet the atmospheric effect and the terrestrial source or cause are not commensurate. Does this denote the relation of marginal utility to exchange value? No one is disposed to dispute the causal connection of utility with exchange value - no utility, no exchange value. But there may be an abundance of utility and yet no exchange value. This shows, at least, that utility alone cannot beget exchange value. On the other hand, there can be no economic exchange without what has been termed marginal utility. This, too, is freely conceded; but does it prove that marginal utility controls the height or amount of exchange value?

After what has been observed with reference to the zone of play enjoyed by exchange value, bounded by the two margins of utility - a zone that may run infinite, ${ }^{26}$ as in the case of the diagram - it may seem superfluous to state that marginal utility cannot be the sole determinant of exchange value. One might as well ignore the sun, and say the ocean is the sole cause of the atmospheric moisture.

The margins of utility mark the upper and lower limits of exchange value. These boundaries are variable; and, however sharp or abrupt the variation in any single case, they always include the point of exchange value, although, owing to the

${ }^{25} \mathrm{We}$ shall have occasion later to notice cases in which the buyer's subjective valuation (higher marginal utility) is entirely displaced as the upper limit of this zone.

${ }^{28}$ This is one of the cases referred to in last note, in which a new limit displaces marginal utility altogether as the upper boundary of this zone. 
width of the zone, this point is not always sensitive to the variation of the limits.

Since these limits measure the intensity of demand, respectively, of buyer and seller, ${ }^{27}$ this office of limitation itself would seem to argue a very large share of the determination of exchange value in favor of demand; unless, indeed, it should appear that there is an external force at work alongside the latter agency, co-operating with it, in the determination of the marginal-utility limits themselves.

The name itself suggests such external force. The thing denoted by "margin" is not involved in the simple concept " utility" or "demand." Neither the concept nor the name "marginal utility" is monogenetic. Neither has a simple origin. The "margin" of supply contributes the element that makes it possible that there should be a specific marginal demand. The realization of the marginal demand is dependent on the presence of a definite measure of supply.

This marginal demand may be due, of course, to an accreditcd or anticipated, as well as to an actual, supply; and this means that the accredited, or anticipated, is in effect actual, in its influence on the factor of demand. Whether supposititious or actual, it is circumstance of supply that is largely responsible for the specific intensity of the demand, or, to put it a little more suggestively, that causes the demand to manifest a specific intensity, as expressed by the marginal utility. ${ }^{28}$

And now it begins to look as though the dominant share in the determination of marginal utility must be assigned to the agency of supply. Such is not the purpose of the argument. Utility obtains independently of any of the circumstances of supply that are due to human agency. Nature has furnished

27 " The withdrawing seller is himself a buyer." - H. J. Davenport, op. cit., p. 283.

${ }^{28}$ The Austrian school recognizes the agency of supply acting on marginal utility. For instance, Mr. Smart closes his treatise, The Theory of Value, with an approved paragraph taken from Jevons, closing as follows: "Labor is found often to determine value, but only in an indirect manner, by varying the degree of utility of the commodity through an increase or limitation of the supply." The qualification “ only in an indirect manner" seems meant to convey the impression that indirectness in some way robs the agent of his function, or neutralizes the 
materials and has endowed them with utility. Man's part has been in the direction of multiplying and diversifying the things suitable to share in the natural bounty. It needs not saying that nature's gift of general utility is the fundamental requisite to the emergence of any quantitative function-specifically, that of marginal utility. To question this would be to question that the waters of the sea are indispensable to the moisture of the air. The agency of supply does not act in the character of a creator of either general or marginal utility, but in the character of a quantitative modifier. With the essence of utility the agency of supply has nothing to do, just as the sun has nothing to do with creating the substance of the vapor. In either case the agency in question has much to do with the quantitative measure of the effect.

In the case of marginal utility, the variation at one time is plainly due to conditions of supply; at another time the change is evidently due to the factor of demand. As an example of the latter, upon the breaking out of hostilities, the marginal utility of all war supplies has a tendency to soar. Again, the caprice of fashion may cause the marginal utility of a commodity to drop with equal abruptness. ${ }^{29}$ On the other hand, the application of improved productive facilities (inventions and the like) has a tendency to increase the output and lower the marginal utility. The converse is also true. ${ }^{30}$ All of which shows that the forces controlling marginal utility are multiple, sometimes exhibiting cumulative, at other times residual, effects, depending on whether the agencies work in harmony or conflict. ${ }^{31}$

effect. But this same indirectness in no wise diminishes the effectiveness of a principle, if serving in a cause that the Austrians espouse. They freely admit that " cost of production regulates value," but this is only a "direct" regulation. The "indirect," or ultimate control is vested in the agency of utility.

The latter part of this paper takes up the argument as to cost of production. As to indirectness, it has just the same effectiveness as directness, and enjoys the merit of referring to an agency one step, at least, nearer the original or ultimate principle of causation.

${ }^{29}$ It may be remarked, in passing, that changes in marginal utility are attended usually (although not necessarily) by changes in exchange value.

${ }^{30}$ The latter part of this paper criticises the Austrian interpretation of these phenomena as affecting the conduction of value between cost and product.

${ }^{31}$ The last argument is not directed against the principle of marginal utility, 
Having seen that the limit set by marginal utility is the resultant of dual sets of forces, we may now enter the precinct presided over by the two margins, the "zone" of exchange value, and study the forces operating directly to fix the ratio of exchange. For this purpose we shall make but slight progress in the realm of simple barter. In the case of the two husbandmen, with their modest store of corn and potatoes, the principle of exchange would likely be extra-economic - friendly feeling taking the place of economic motives in making an exchange. We may as well repair to a larger market at once, and, for our purpose, the diagram will furnish a fruitful field of study.

We saw, in the earlier discussion, that competition among the purveyors of food was one effective agency. But that does not exhaust the category. If the supplies of the other two groups of commodities were to become either greater or less, the point $E^{\prime}$ would be sensitive to the change. The more abundant these supplies, the higher the exchange value of food, and vice versa. So, operating at the same time with circumstances of competition among sellers, we have circumstances of provision among buyers. A barely sensible competition, bordering on monopoly of food, co-operates with redundant supplies in the remaining groups to elevate the point $E^{\prime}$. Energetic competition, on the other hand, co-operates with scant supplies to depress this point. It is evident that a transverse pairing of these forces will manifest neutralizing effects. Thus we have the various forces working in alternate excepting so far as the latter is interpreted and emphasized as conflicting with, and superseding, the classical doctrine of supply and demand. Consider the following :

I. Training of youth makes for good citizenship.

2. The family institution makes for the training of youth.

The validity of proposition $I$ is unquestionable, and yet the causal relation leading to good citizenship finds adequate expression only when the second proposition supplements the first. The relation is as well stated in the form: The family institution makes for good citizenship through the instrumentality of training of youth. Just so the causal principle (as presumed for argument's sake) relative to exchange value is adequately stated in the form: Supply and demand regulate exchange value through the instrumentality of marginal utility.

It must not be inferred that this formulation of the law of exchange value is sanctioned by this paper. It is used simply in illustrating the force and compass of the current argument. 
unison and antagonism in the determination of the specific height of exchange value

Circumstances of provision among buyers must be regarded as a demand function. Buyers have a limited quantity of utilities with which to balance their purchases. This specific supply, "circumstances of provision," may be called the "purchasing power" 32 of the buyers, as against the "subjective valuation," or "marginal utility," which expresses the intensity of their deinand.

In the case of the diagram the marginal utility of food is infinity. The purchasing power is infinitely less, being the sum of the supplies of the two inferior groups; it marks the upper limit of exchange value in our illustration, and is represented in the diagram by $P^{\prime} .{ }^{33}$

In case of a strict monopoly and of exchange made on a purely economic basis, the price $P^{\prime}$ would be realized. ${ }^{34}$ If other considerations are influential, or if the conditions are competitive, the exchange value would settle at some lower altitude, $E^{\prime}$.

This auxiliary agency in the determination of exchange value is on the demand side, but is entirely distinct from marginal utility, having nothing of the subjective character of the latter. It is a function of the objective state of the demand market - of

${ }^{32}$ Akin to "effectual demand" of classical writers, " equation of supply and demand" of Mill. Marshall, in his Principles of Economics, at p. 567, in a note on Ricardo appended to Book V, chap. xiv, of the fourth edition, writes: "For the price which the various purchasers in a market will pay for a thing is determined not solely by the final degrees of utility to them, but by these in conjunction with the amounts of purchasing power severally at their disposal."

${ }^{33}$ In harmony with the plan of the diagram, it is necessary to indicate purchasing power indirectly. The direction $O Y$ is reserved for the measurement of ratios. $N F^{\prime \prime \prime}$ and $N F^{\prime}$ measure the ratios of the utility of a unit of food to that of the unit of exchange. Calling the unit of exchange I, the magnitudes, $N F^{\prime \prime}$, $N F^{\prime} N E^{\prime}$ are, of course, the ratios themselves.

$N P^{\prime}$, consistently with this analysis, measures the price at which a unit of food must be sold in order that the whole quantity sold will just exhaust the supplies of other commodities (purchasing power) in the hands of purchasers, reserving, if you please, as much of these latter supplies as is necessary to maintain life.

${ }^{34}$ Of course, under the assumption of the diagram that shelter is not absolutely essential to life. Under the contrary assumption the price would fall below $P^{\prime}$. 
the supplies in the hands of the buying public. It marks one more entry in the category of causation of exchange value.

In our illustration, $P^{\prime}$ takes the place of $I$ as the upper limit of exchange value. It will be remembered that, according to our analysis, exchange value never coincides with either of the marginal-utility limits. In the case of the diagram the upper marginal limit is infinitely beyond reach. A new inferior altitude is installed as the upper limit of exchange value, representing the sum-total of the objective state of the market on the demand side. ${ }^{35}$ This point $P^{\prime}$ will continue to mark the upper limit, as the food supply increases, until the curve of marginal utility, $F^{\prime} F$, descends to the same altitude as $P^{\prime}$, say at $P .^{36}$

We may summarize the main results thus far attained as follows :

Exchange value is a complex function, not a simple one.

This function is dependent immediately on the circumstances of competition among the sellers, on the one side, and on the circumstances of provision (purchasing power) among the buyers, on the other side.

Again, concomitant with the above agencies, exchange value is dependent on the concrete variable, aggregate of supply in the hands of sellers, on the one hand, and on the abstract variable intensity of demand by buyers, on the other.

The resultant of these latter agencies is registered primarily in the variation of the marginal-utility limits themselves, and secondarily in the potential movement of exchange value which the variation of the limits involves. In other words, this effect is manifested in the movement of the "zone" of exchange value,

${ }^{35}$ See note 33 .

${ }^{36}$ Evidently $P$ will have the same altitude as $P^{\prime}$ only on condition that the supplies of the inferior groups - the demand groups of the diagram - remain constant, while food increases. The cases in which, in our usual social environment, marginal utility would be displaced as the upper limit of exchange value are perhaps unimportant as practical problems, but theoretically they are real. In primitive life, however, as well as in lonely wilderness, desert, or pioneer circumstances of living, this displacement would be common.

It will be noticed that the "zone" of exchange value is contracted by the installation of a new upper margin - so that, strictly speaking, this zone never is infinite in compass. 
carrying with it ordinarily, although not necessarily, a variation in the height of exchange value. ${ }^{37}$

It is an easy step from the consideration of exchange value to that of "cost of production." And here, as was stated at the beginning of this article, the theory of the Austrians has the advantage that comes from first reducing the notions to be considered to a single category. Value has been offset by value in their formulation, and sacrifice, as an abstract concept, plays no essential rôle in the calculation.

Cost, in the sense of pain or irksomeness, is not an integral part of the system of the Austrians. Apparently they have taken up the thought because they found the thread of it running all through economic discussion. By first interpreting cost as a value-concept, they have plausibly correlated it with their own doctrine.

The refutation of the principle of marginal utility, as the rule of value, carries with it the refutation of the Austrian doctrine as to the reflection of value from product to cost. All the argument employed in the examination of the evidence of the former law may find parallel service in the latter inquiry; it requires only a slightly different setting.

Cost of production determines the value of the product; and yet that is not to say that there is no law of limitation - a limitation issuing out of the very heart of the product. The determination is such that the exchange value is limited to the altitude of marginal utility. Does this restriction signify the reversal of the law of determination? It seems to be so construed by the Austrian school. The eagle has considerable liberty to soar, although his flight is confined within the bounds of his buoyant environment. Just so the sovereignty exercised by cost over the

${ }^{37}$ The zone movement, it should be noticed, is manifold, the zone itself being elastic, expanding and contracting, spreading by means of the elevation of the upper margin, or by the depression of the lower, or both; also vice versa, and transversely. In addition to this, there is a possible translation of the entire body of the zone. This picture makes it plain that there may be a change in the altitude of the limits at the same time that the height of exchange value is stationary. 
value of the product has its limitation, which, however, no more than in the case of the eagle, means the relinquishment of its rule.

Let us follow the lead of the Austrians in the matter of interpreting costs as expenses, and, dismissing the causal sequence for the present, it will be profitable to study, for itself, the relation of equality subsisting between expenses and product. Either one is necessarily the measure of the other; and in this sense, at least, it may be $s$ id that either determines the other. The whole is neither greater nor less than the sum of its parts, so that the equilibrium between expenses of production and the value of the product is simply a case of equilibrium between the parts and the whole. Exchange value, or price, of the product, can, in every instance, be resolved into its elements, and these elements are the expenses of production. ${ }^{38}$ Our study of negative functions ${ }^{39}$ will enable us to understand the cases that show an apparent discrepancy.

Let us dissect the exchange value, or price, of the product. We have (I) the wages of labor and (2) the interest of capital. Here are two elements that are nearly always present; and, aside from previous products, such as raw material, and such incidental expenses as taxes, a logical differentiation would probably make these two species of emolument exhaust the entire category. Rent, ${ }^{40}$ which might be counted a third element, and the profit of the entrepreneur, a possible fourth, may be listed, the former under interest, and the latter under wages. ${ }^{41}$ For our present

${ }^{38}$ Of course, the only chance of a controversy here affects the content of " expenses of production." This paper takes the ground that expenses of production properly include all expenses incurred in transforming materials into a consumption product - that is, a product in the hands of the consumer. It is not worth while to discuss the propriety of the nomenclature; "expenses of acquisition" will serve the purpose. The sole object at present is to differentiate the various elements that constitute the sum-total.

${ }^{39}$ See pp. 401 ff.

${ }^{40}$ It is not necessary to go into the controversy as to whether rent is a joint determinant of value. We are now examining the elements of value that we find in an individual entrepreneur's specific product - which is quite a different problein from that of determining the elements that fix the value of a product considered as a genus, or as representing an entire branch of industry.

${ }^{41}$ If anyone can find other elements in the schedule of expenses, they may be added to our list. Our work here is a task of dissection, purely - dissecting the structure of price. 
discussion it will be convenient to list profit ${ }^{42}$ distinct from wages, not because it is radically different, but in view of a certain characteristic bearing on our classification, and which does not apply to wages, ${ }^{43}$ namely, its liability to lapse from positive to negative. $^{44}$ Let us consider a specific example:

A shoe factory turns out in a season a product of $\$ 1,000,000$. The wages, interest, rent, previous products, and incidentals amount to $\$ 900,000$, leaving a profit of $\$ 100,000$. Usually ${ }^{45}$ the entrepreneur forecasts the returns from the product so as to allow a profit of a positive character. But, if his particular product should suffer a sudden depreciation, by change of fashion or other cause, the returns might not leave a margin of positive profit. With our negative conception, however, a profit always obtains. If in the example, the product yields but $\$ 800,000$, the expenses of production will schedule somewhat as follows :

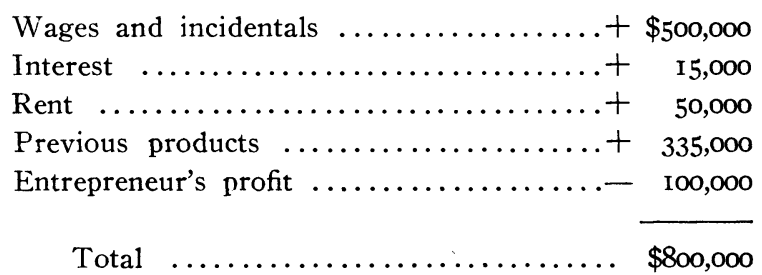

${ }^{42}$ It is a question whether profit as well as rent should not be excluded from the list of "determinants" of exchange value. But, in examining the value of an individual's product, there would generally be a discrepancy, if profit, in addition to rent, were not included - a discrepancy sometimes positive, sometimes negative. The exceptional case would be when the profit is zero.

${ }^{43}$ Wages of subordinates sometimes become negative. A commission salesman may earn less than his expenses. In this case, however, the negative element does not enter into the exchange value, since the deficiency is made up from the salesman's independent resources - unless the entrepreneur advances such expenses and is not indemnified, in which case the deficiency due to this cause serves to abridge the profit of the entrepreneur, and through this door finds its way into the price.

"We do not distinguish price and exchange value in this connection. The differences are such as would affect the individual shares of the factors of production; they would not disturb the equilibrium that we are examining, and they need not complicate our calculation.

${ }^{45}$ We leave out of consideration extraordinary commercial losses from bad debts, fire, flood, earthquake, or any other catastrophe of nature. 
In the case of our primitive husbandmen, ${ }^{46}$ wages, interest, rent, profit, etc., coalesce into one complex mass, the same man being laborer, capitalist, landlord, and entrepreneur. The lump sum with the value of previous products evidently make up the exchange value. With De Quincey's musical snuff-box, the extortionate price was the case of a monopolistic advantage pushed to the limit, the huckster having exact knowledge of his victim's weakness. The profit, added to the other expenses, as before, made up the price.

It is needless to multiply illustrations. All we have done so far is to resolve a whole into its constituent parts. The process itself says nothing of causal sequence one way or the other.

But now, in our analysis, the determination of the entrepreneur's profit by the process of subtraction lends color to the view that the value of the product determines the value of the factors of production. There seems to be a residual share. We have, at best, as the data on the expense side, wages, interest, rent, previous products, and incidentals. The value of the product is required in order to evaluate the remaining element of profit. The product thus determines the final share, and, as a corollary, it determines also the sum-total of expenses.

This summing-up does no injustice to the logic of the situation, so far as the immediate facts are concerned. The trouble is that these immediate facts are bound up with others that are antecedent, and that are not taken account of in the illustration. In taking a specific case, we have isolated one member of a craft, and he has been obliged to fit himself into conditions preestablished. One manufacturer, out of a hundred or more, making a standard class of goods, cannot regulate prices. If he has a monopoly in a particular branch, the case is different. He can then dictate to the market by adding an arbitrary profit to the remaining expenses. In lieu of a monopoly, the entire craft, as the resultant of more or less intelligent calculation and competitive enterprise, and in the light of experience, fixes the price at a certain point, which, of course, is not always stable even through the season. Every member of the craft adapts his

${ }^{40}$ Pp. 395 ff. 
mechanism of production to the price thus prearranged, and his individual profit is dependent on the inevitable contingencies of business life. ${ }^{47}$

As has been stated, independent proof that cost determines value is superfluous, since it is involved in the refutation of the marginal-utility theory. But it will perhaps be profitable to notice some of the evidence offered by the adherents of the new school.

Mr. Smart apparently considers the following a decisive test of his doctrine:

The proof of this conduction [from product to cost] is not far to seek; it is found in the common phenomenon of dead stock. However great the cost expended on an article, if the public will not have it, all the costs in Christendom will not give it a value. . . . Suppose that an article, of which there is a stock, goes out of fashion, the value and the price of it fall at once. ${ }^{48}$

This is a special case noticed on page 405 , in which the sudden decline of utility registers its effect in the contraction of the zone of exchange value by a depression of the upper margin, the lower margin (the seller's subjective valuation, or marginal utility) remaining practically as before, at zero.

One could find equally cogent reason for tracing the conduction of value in the reverse direction by the following evidence: When new appliances in production greatly reduce the cost, the exchange value of the product drops to conform to the new schedule of cost, notwithstanding the fact that the marginal utility remains as before.

Of course, the marginal utility would decline with the multiplication of the products, but the decline of "price" takes place as a sensitive effect to the decline of cost always, unless other conditions supervene. These other conditions - at least one other condition is apt to supervene in such cases, namely, a monopoly enjoyed by the inventor of the new appliances. Let there be the same condition of competition under the new régime of cost as under the old, and the price will be sensitive to the change of cost as surely as effect follows cause. And notice, too, that if

${ }^{47}$ Of course, even in the case of a monopoly, the determination of price is subject to the limitation set forth in our previous discussion.

${ }^{48}$ Introduction to the Theory of Value, pp. 68, 69. 
price is maintained by reason of a monopoly, this monopoly is a factor in circumstances of supply, and not of demand.

In the case just cited (improvement of productive facilities), the Austrian school concedes that cost is the direct determinant of value, insisting, however, that the ultimate principle of determination still resides in the utility of the product. When pressed at this point, we have an exhibition of industrious and skilful parrying. According to the argument, it is not the marginal utility of the specific product that determines the price, but that of some other product related to the former by the fact of dependence on the same general organization of production. This case is so important that it is worth while to state the argument in full. Wieser's account is as succinct as any, and to the point; we use his version:

There are, however, cases where, without influencing the quantity of production, the cost directly determines the value of the commodities. It must suffice here to illustrate this by a single example. Suppose the railroad system of a country to be complete, and consequently the general demand for rails is limited to that quantity which is required to replace the wear and tear. Let us suppose, furthermore, that the value of iron, owing to an immense increase in the production of that metal, considerably decreases - what will be the effect on the value of rails? Their utility does not apparently change, nor the quantity produced; nevertheless their value will decrease for the very reason that the cost has lessened. If the production of rails were monopolized, the former price could be maintained, and the fact that the rails had decreased in value would only come into account in the internal production. Free competition, however, will compel the producer to adapt the price to the rectified valuation, and to allow the consumers to participate in the reduction of the value.

Without further analyzing these cases, mentioned as illustrations, I shall only show their general theoretical importance. We have here to do with a new application of the "law of marginal utility." The utility of the rails no longer depends upon their possession, nor even upon their marginal utility, but only upon the still lower marginal utility of the material, labor, etc., which are requisite for their production. The value of these materials, labor, etc., is determined by that of commodities having a still lower marginal utility than the rails; for example, ordinary tools. The value of the rails is determined, therefore, (I) by the quantities of iron required; and (2) by the utility they have in their most unimportant application in other production processes. Although the rails do not owe their value to their utility, they owe it to some 
kind of utility, primarily to that of the means of production employed; finally to the marginal utility of certain other commodities. ${ }^{40}$

According to this reasoning, the value of products generally, in the present industrial organization, must be traced, not to their own utility, but to the utility of other products, so-called marginal ones. It would be interesting to know how Wieser would handle the dialectics of his illustration, in case there were no uses for iron of less utility than steel rails. Obviously, in this case of definitely limited demand of iron products, when the cost was reduced, one result would be found in the transfer of parts of the labor and capital, or part of the ensemble, to other branches of industry. Wieser would probably argue that, in this event, the determination of value must be traced into another industry, where may be found a commodity of the proper utility, that is produced by the same cost. If we push this process of finding a vicarious utility to its theoretical limit, we should have the entire category of commodities tracing their value to the marginal utility of some one individual commodity.

But we need not depend on the evidence of cumulative probability that the Austrian reasoning is fallacious. There is a simple proof right at hand. To return to the steel-rail illustration, it is argued that the reduced value of steel rails is determined by the lower utility of the marginal iron product (of the same cost), say, steel braces for buildings, rendered marketable by the new régime of cost. What Wieser meant, unless he was unconsciously influenced by the exigencies of his theory - at least, what an impartial observer would mean by the statement that the value of steel rails, under the circumstances, is determined, not by the marginal utility of the rails, but by that of the braces - was that the utility of the braces is commensurate with the value of the rails. This is quite a different matter, as we have seen. ${ }^{50}$ The trouble comes about from the use of the ambiguous word "determine." It may refer to the result obtained by measuring, or it may refer to a causal agency. It will be readily shown that the term is applicable, in this connection, only in the former sense.

49 Annals of the American Academy, Vol. II, pp. 6r8, 6rg.

${ }^{\text {so }} \mathrm{Pp} .403 \mathrm{ff}$. 
First, let us segregate the real factors of the problem. There are (I) the steel rails, of comparatively high utility; (2) the steel braces, of comparatively low utility; (3) the exchange value of the rails; and finally (4) the cost of production of the latter.

Next, let us separate the constant factors of the problem from the variable. First, the utility (marginal) of the rails is supposed to remain constant, and, secondly, that of the braces is also supposed to be a definite amount. The remaining factors, however, the exchange value of rails and the cost of the latter, have changed. It is a truism of philosophy that a change in either cause or effect involves a change in the other. The marginal utility neither of rails nor of braces suffered a change. ${ }^{51}$ Consequently these two factors may be dismissed from consideration; and we are left to the conclusion that the change in the value was due, not to utility at all, but to the decreased cost, which showed a commensurate change. So far as the causal agency is concerned, not only was the decline in exchange value due to decreased cost, but this decreased cost was the direct agency that enabled producers to market a commodity of lower marginal utility than rails. The causal current flowed from cost to the exchange value of rails, and also to the marketability of braces. ${ }^{52}$

We may subject the Austrian theory to a test of a somewhat different character. The adherents to the Austrian faith cite the

${ }^{51}$ Of course, it is not meant that these functions (marginal utility of rails and of braces) are devoid of mutability, as a permanent condition; but, during the decline of cost and of exchange value of rails, the marginal utility of the latter is supposed to remain as at first. The marginal utility of braces was a lower constant, awaiting the proper leveling of cost in order to become available in exchange. At a subsequent period, under other circumstances, both these utilities might fluctuate.

${ }^{52}$ It will be remembered that the rule of cost is subject to a certain limitation residing in marginal utility, just as the liberty of flight for the eagle is subject to the limitation imposed by the state of atmospheric buoyancy. This limitation in production manifests itself by the exclusion of commodities whose utility is not sufficient to warrant the expense of producing. The expenses of production would demand a higher price than is represented by the utility. The fact that utility itself can do nothing toward reducing the price to a marketable basis shows that the causal agency must be sought elsewhere. Marginal utility simply exercises the office of limitation; and even this office is a passive one, since the amount, or height, of the marginal utility itself is dependent on the joint action of supply and demand. See pp. $404 \mathrm{ff}$. 
fact that commodities tend to decline in exchange value with increase of the product. ${ }^{53}$ There are cases that show even a decline in the total exchange value, when the product is extended. This they look upon as evidence that exchange value originates in the product. They forget for the time being that these phenomena are characteristic of individual isolated cases - that, at the same time, other products must show an increase in exchange value, to balance the decline of the few. There is no such thing as a general decline of exchange value.

To suppose that high wages make high values is to suppose that there can be such a thing as general high values. But this is a contradiction in terms: the high value of some things is synonymous with the low value of others. ${ }^{35}$

The fact is that if all commodities were multiplied in the ratio of existing supplies, not only would the balance of exchange be maintained, but the total exchange value of the ensemble would increase in proportion to the increase of physical product. We may offer a simple proof of this proposition, as follows: Suppose all commodities were blended into two complex ones of equal mass. Take for the standard of exchange a complex unit containing a half pound each of these masses. It is easy to show mathematically that if the two masses increase, pari passu, the total exchange value, referred to the standard of exchange, would be in direct ratio to the physical increase. ${ }^{55}$

Perhaps the following is more intelligible than the strictly mathematical method to the average reader: Blend the two commodity masses into a universal single complex. Having the standard of exchange already set off (one pound of this mass), it matters not that with a single utility mass, there would be no economic exchange. The expedient of obtaining the standard before resorting to the final act of blending enables us to get the

${ }^{53} \mathrm{Mr}$. Smart, at p. 33 of his Theory of Value, says: "Now one of the commonest phenomena of the market is that, ceteris paribus, increase of supply brings down value and decrease of supply sends it up." Mr. Smart also makes a chapter from Wieser's Natural Value, on the same theme, serve as an appendix to his own volume.

${ }^{54}$ J. S. Mill, Principles of Political Economy, Vol. I, p. 565.

${ }^{35}$ If anyone is interested in the mathematical proof of this proposition, he is referred to Value in its Relation to Interest, in the December, r9or, number of this Journal. 
total of what would be called the exchange value, if the mass were again resolved into its elements. This true image of exchange value would be expressed by the weight in pounds. No matter what vagaries of value a few isolated elements might manifest, if detached, these idiosyncrasies are neutralized in the ensemble, so as to show a value increasing in proportion to mass.

The conception of marginal utility has been useful in that it has provided a function convenient in defining the zone of exchange value. But the marginal-utility principle set up for the ultimate determination of exchange value is inadequate and misleading.

The conclusions arrived at in this paper are in substantial accord with the older economists. The radical shifting in the view of value represented by the new school makes it seem not out of place to undertake to set the old doctrine in its true relation to modern terminology, which has necessitated some change in the classical formulation.

R. S. PADAN.

Chicago. 